\title{
Causes of Adverse Pregnancy Outcomes and the Role of Maternal Perio- dontal Status - A Review of the Literature
}

\author{
Dr. Jagan Kumar Baskaradoss ${ }^{1 * *}$, Amrita Geevarghese ${ }^{1}$ and Abdullah Al Farraj Al Dosari ${ }^{2}$ \\ ${ }^{I}$ Dental Implant \& Osseointegration Research Chair (DIORC), College of Dentistry, King Saud University, Saudi Arabia \\ ${ }^{2}$ Dental Implant and Osseointegration Research Chair, Prosthodontics and Implantology, College of Dentistry, King Saud \\ University, Saudi Arabia
}

\begin{abstract}
Preterm (PT) and Low birth weight (LBW) are considered to be the most relevant biological determinants of newborn infants survival, both in developed and in developing countries. Numerous risk factors for PT and LBW have been defined in the literature. Infections of the genitourinary tract infections along with various biological and genetic factors are considered to be the most common etiological factors for PT/LBW deliveries. However, evidence suggests that sub-clinical infection sites that are also distant from the genitor-urinary tract may be an important cause for PT/LBW deliveries. Maternal periodontal status has also been reported by many authors as a possible risk factor for PT and LBW, though not all of the actual data support such hypothesis. The aim of this paper is to review the evidence from various published literature on the association between the maternal periodontal status and adverse pregnancy outcomes. Although this review found a consistent association between periodontitis and PT/LBW, this finding should be treated with great caution until the sources of heterogeneity can be explained.
\end{abstract}

Keywords: Etiology, low birth weight, literature review, maternal periodontal status, preterm delivery, pregnancy.

\section{INTRODUCTION}

Preterm (PT) delivery is defined as delivery before the end of 37 weeks of gestation (less than 259 days). The international definition of low birth weight (LBW) adopted by the 29th World Health assembly in 1976 is a birth weight of less than 2500 grams [1]. PT infants who are born with a LBW are termed preterm low birth weight (PLBW). The rate of PT birth appears to be increasing world-wide and efforts to prevent or reduce its prevalence have been largely unsuccessful. The importance of PT and LBW deliveries comes from their capacity to predict the increased risk of mortality among infants born with this condition. PT births account for $75 \%$ of perinatal mortality and more than half the long-term morbidity [2]. Moreover, World Health Organization (WHO) aims to reduce the number of LBW deliveries, since this is a known predictor of childhood morbidity and mortality [3]. WHO had given the global estimates of the prevalence of LBW [4]. The rate of PT/LBW deliveries differ among different countries and also between different ethnic races. The highest rates of LBW were reported for Asia and the lowest rates were reported for North America and Europe. In the USA and in the UK, women classified as black, AfricanAmerican, and Afro-Caribbean are consistently reported to be at higher risk of PT delivery. Black women are also three to four times more likely to have a very early PT birth than women from other racial or ethnic groups [5]. In developing

*Address correspondence to this author at the Dental Implant \& Osseointegration Research Chair (DIORC), College of Dentistry, King Saud University, P.O Box: 60169, Riyadh 11545, KSA; Direct :+966 14697538, Mob: +966 559016991; E-mail: drjaganb@gmail.com

$1874-2106 / 12$ countries, most LBW is related to intrauterine growth retardation (IUGR), whereas in developed countries most LBW is related to PT birth. Consequently, the identification of risk factors for PT birth which are amenable to intervention would have far-reaching and long-lasting effects.

\section{CAUSES FOR ADVERSE PREGNANCY OUTCOMES}

Defining risk factors for prediction of PT/LBW birth is a reasonable goal for several reasons. This helps in the identification of high risk group women, which in turn, allows the initiation of risk-specific treatment. Another reason is that, the identification of risk factors would help in defining an appropriate population where specific interventions could be studied. Finally, this would also help in providing important insights into mechanisms leading to PT birth [6]. The primary factors causing PT/LBW infant deliveries are high or low maternal age (>34yrs and <17yrs), smoking, alcohol or drug use during pregnancy, inadequate prenatal care, race, maternal demographic characteristics, hypertension, psychological characteristics, adverse behaviors, multiple pregnancies, nutritional status, diabetes, genitourinary tract infections, uterine contractions and cervical length, and biological and genetic markers [7-11]. There is also a raised risk of PT birth in pregnancies arising within close temporal proximity to a previous delivery [12]. The mechanism for the recurrence is not always clear, but women with early spontaneous PT births are far more likely to have subsequent spontaneous PT births; women with indicated PT births tend to repeat such births [13]. Multiple gestations-accounting for only 2$3 \%$ of infants - carry a substantial risk of PT delivery, and result in $15-20 \%$ of all PT births. Nearly $60 \%$ of twins are born PT. Uterine over distension, resulting in contractions is 
believed to be the causative mechanism for the rate of increased spontaneous PT births [14].

Nutritional status during pregnancy can be described by indicators of body size such as body-mass index (BMI). It was reported that obese women are more likely to have infants with congenital anomalies, such as neural-tube defects, and these infants are more likely to be delivered PT. Obese women are also more likely to develop pre-eclampsia and diabetes, and have indicated PT births associated with these disorders [15]. On the contrary, a more recent study reported that a low pre-pregnancy BMI is associated with a high risk of spontaneous PT birth, whereas obesity can be protective [16]. Low maternal weight gain has also been shown to increase the risk of PT birth in some studies. Low maternal weight gain and inadequate pre-natal care are risk factors considered weakly associated with PT birth in retrospective studies [17].

Investigation of work-related risk factors are made difficult by various confounding factors; however, working long hours and undertaking hard physical labour under stressful conditions have been associated with an increase in incidence of PT births [18, 19].

Maternal medical disorders, such as thyroid disease, asthma, diabetes, and hypertension, are associated with increased rates of PT delivery, many of which are indicated because of maternal complications. Mothers experiencing high levels of psychological or social stress have an increased risk of PT birth [7]. Clinical depression during pregnancy has been reported in up to $16 \%$ of women, with up to $35 \%$ having some depressive symptoms [20, 21]. Although the results are inconsistent, several reports suggest a relation (risks generally rose <2-fold) between depression and PT birth [22]. Depression is associated with an increase in smoking, and drug and alcohol use; therefore, the relation between depression and PT birth might be mediated by these behaviors. Nevertheless, in some studies that adjusted for smoking and drug and alcohol use, the association between depression and PT birth persisted, suggesting that this relationship might be caused by more than confounding [23].

Microbiological studies suggest that intrauterine infection might account for $25-40 \%$ of PT births. Microorganisms can gain access to the amniotic cavity by: (1) ascending from the vagina and the cervix; (2) haematogenous dissemination through the placenta; (3) accidental introduction at the time of invasive procedures; and (4) by retrograde spread through the fallopian tubes. The most common pathway is the ascending route. Although most investigators believe that ascent happens during the second trimester, the timing is unknown [24]. It has been suggested that spontaneous pre-term labour is commonly associated with bacterial vaginosis, which elicits and inflammatory response which may lead to placental damage [25]. The associations between elevated serum concentrations of Interleukin-6 (IL-6), C - reactive protein (CRP) and matrix metalloproteinase - 9 (MMP-9) in fetal and/or neonatal compartments and preterm delivery and/or neonatal morbidities have been recognized [26]. IL-6 is a useful marker for intrauterine infection, PT births, and neonatal morbidities.
IL-6 is a proinflammatory cytokine which is a major mediator of host response to inflammation and infection, and is an early marker of the acute phase response. The presence of increased concentration of IL-6 in cervico-vaginal fluid [14], amniotic fluid [27], fetal blood [28], umbilical cord blood at delivery [29], and neonatal blood [30] are independent risk factors for PT births. CRP may not be a specific marker for infection but can be considered as a reliable marker for both acute and chronic inflammatory conditions. An increase in the CRP concentrations in the amniotic fluid[31] and umbilical cord at delivery[32] are associated with intrauterine infection and PT delivery. Similarly, the presence of increased concentrations of MMP-9 in the amniotic fluid [33] and neonatal blood [34] were associated with intra-amniotic infection and PT birth. An irregular cytokine response can stimulate prostaglandin and the release of MMPs, causing uterine contractions and membrane rupture, respectively, leading to the induction of labour $[35,36]$. Studies of human myometrium have also shown that cytokine release is stimulated by circulating endotoxins i.e. lipopolysaccharides (LPS) [37]. The cytokine network is challenged by bacterial endotoxins and thus may also be involved in the pathomechanisms contributing to preterm deliveries.

However, approximately $25 \%$ of PLBW deliveries occur without any of the risk factors discussed in this section, which emphasizes the limited understanding of the causes and pathophysiology of the problem [38].

\section{PERIODONTITIS AND PREGNANCY}

\section{Landmark Epidemiological Evidence}

Research in the area of periodontal medicine marks a resurgence in the concept of focal infection [39]. It was in 1996 that researchers first reported a relationship between maternal periodontal disease and delivery of a PT infant. Periodontal disease is a Gram-negative anaerobic infection of the mouth that affects up to $90 \%$ of the population [40], and has been demonstrated to be higher in pregnant women [41]. The 1996 study by Offenbacher and colleagues suggested that maternal periodontal disease was associated with a seven-fold increased risk of delivery of a PLBW infant. These authors concluded that about $18 \%$ of PLBW cases might be attributable to periodontal disease. After controlling for known risk factors, the results of this study was the first to show that periodontitis was a significant risk factor for PLBW [42]. Later, Dasanayake et al. [43] confirmed this finding by showing that women with healthy periodontal status had a lower risk of having adverse pregnancy outcomes.

\section{Recent Epidemiological Evidence}

Numerous studies have been conducted across the world to identify the association between periodontal disease and adverse pregnancy outcomes. A cohort study performed by Mobeen et al. [44], concluded that pregnant women had high levels of moderate-to-severe dental disease. Also, stillbirth and neonatal and perinatal deaths increased with the severity of periodontal disease. Saddki et al. [45] found that the relative risk of PT birth was 4.2 times higher for women with periodontitis as compared to those without periodontitis (95\% CI: 2.01-9.04). Similarly, Pitiphat et al. [46] concluded 
that periodontitis was an independent risk factor for adverse pregnancy outcomes. Periodontitis was identified as a risk indicator for LBW similar to other risk factors already recognized by obstetricians [47]. A study by Khader et al. [48], found that the extent and severity of periodontal diseases was associated with an increased odds of PLBW delivery. Another study found that periodontal disease is associated with a premature or extremely premature birth [49]. Ryu et al. [50] in a case control study found that scaling before pregnancy was significantly different between the PTB cases and the controls. The prevalence of Porphyromonas gingivalis also was significantly different between the groups. In a more recent case-control study [51], it was found that mothers with periodontitis had a nearly threefold increased risk of PT delivery.

\section{Intervention Studies}

The need for randomized clinical trials (RCTs) is necessary to further evaluate the causal relationships between periodontal disease and PLBW. A prospective study found that performing scaling and root planning (SRP) in pregnant women with periodontitis may reduce PT births [52]. A randomized clinical trial [53] reported that, women who were treated for marginal periodontitis before the 28th week of pregnancy had a lower rate of PLBW (1.84\%) compared to women who received treatment delivery $(10.11 \%)$. In a study by Tarannum et al. [54] on the effect of periodontal therapy on pregnancy outcome in women affected by periodontitis it was found that non-surgical periodontal therapy can reduce the risk for PT births in mothers who are affected by periodontitis. Michalowicz et al. [55] provided the treatment group patients with SRP before 21 weeks of gestation and the control group with the same treatment after delivery. They found that, treatment of periodontitis in pregnant women improved periodontal disease and is safe but had little effect on the birth outcome. But, here the authors themselves accept the possibility of a delayed intervention which could have influenced their result and a non-significant reduction in spontaneous abortion or stillbirth with periodontal treatment was observed. A recent study also found that, though comprehensive periodontal treatment significantly improved periodontal health, no reduction of PTLBW rates could be achieved [56].

\section{Microbiological Evidence}

It has been demonstrated that transient bacteremia commonly occurs in subjects with periodontitis as well as in those with gingival inflammation, and the bacteria or their products may conceivably reach the placental tissues providing the inflammatory effect for labor induction [57]. Four organisms associated with mature plaque, and progressing periodontitis are Tannerella forsythia (T. forsythia), Porphyromonas gingivalis (P. gingivalis), Aggregatibacter actinomycetemcomitans (A. actinomycetemcomitans), and Treponema denticola (T. denticola) [58].

Madianos et al. [59] identified the microbiological and biological mechanisms between clinical periodontal disease and PT delivery. Maternal plaque, maternal serum and fetal serum samples were collected and analyzed. From this study it was concluded that the highest prematurity rates occurred in mothers who did not mount an adequate immunoglobulin
(IgG) response to the bacteria like $P$. gingivalis, Bacteriodes forsythus (B. forsythus) and $T$. denticola. A significant finding from this study was the highest prematurity rate in mothers who did not mount a robust immunoglobulin ( $\operatorname{IgG})$ response to the bacteria from the "Red" complex, such as $P$. gingivalis, B. forsythus and T. denticola.

Various animal models have explored the relationship between maternal infection and periodontal bacteria. Animal models are essential research tools for investigating the pathways that promote preterm parturition and for testing therapeutic interventions. A study of pregnant mice showed that $F$. nucleatum may be transmitted hematogenously to the placenta and cause adverse pregnancy outcomes [60]. In an alternative mouse model using $P$. gingivalis, systemic induction of maternal immune activation (MIA) lead to fetal growth restriction in every litter, but not in every fetus. Importantly, $P$. gingivalis DNA was found only in the placentas of affected fetuses, and those placentas showed elevation of pro-inflammatory and reduction of anti-inflammatory cytokines [61]. These results link cytokines with fetal morbidity, and they highlight the importance of heterogeneity among placentas within the same uterus. However, a number of major drawbacks to the use of animal models have been reported. The significantly shortened gestation of rats and mice when compared with humans, their small anatomical size and elevated litter size limits the usefulness of these models [62].

\section{Systematic Reviews}

Chambrone et al. presented systematic reviews of prospective cohort studies [63] and RCTs [64]. About 81\% of the reviewed articles found an association between periodontitis and PT/LBW delivery. They analyzed 8 studies, of which about $60 \%$ showed that periodontal treatment may reduce the incidence of PT/LBW deliveries. Another systematic review [65], concluded that the risk of preeclampsia increased in women with urinary tract infection and periodontitis. Review of RCTs reported that, majority of the studies found significant reduction in the incidence of preterm deliveries after non-surgical periodontal treatment [66].

\section{Meta-analysis}

Exploring the possible reasons for heterogeneity between studies is an important aspect of conducting a meta-analysis. Numerous meta-analysis have into the association between periodontal disease and PT/LBW. Khader and Ta'ani [67] included two case-control studies and three prospective cohort studies in their meta-analysis. They reported an overall adjusted odds ratio of preterm low birth weight to be 5.28 (95\% CI, 2.21 to $12.62 ; \mathrm{P}<0.005)$, and an overall adjusted odds ratio of a delivery of either PTB or LBW to be 2.30 (95\% CI, 1.21 to $4.38 ; \mathrm{P}<0.005)$. A larger meta-analysis involving 17 studies, reported a similar association [68]. However, they also observed that better quality studies reported lower association strength and hence the caution should be exercised while interpreting the values. Another meta-analysis which included only RCTs did not support the hypothesis that periodontal therapy reduces preterm birth and LBW indices [69]. A more recent study that included only RCTs indicated statistically significant effect in reducing risk of preterm birth for scaling and root planing in preg- 
nant women with periodontitis, for groups with high risks of preterm birth [70].

\section{BIOLOGICAL PLAUSIBILITY}

It is important to understand the underlying biologic mechanisms for the relationship between periodontal disease and adverse pregnancy outcome in order to provide a rationale for therapeutic interventions. During pregnancy, progesterone increases vascular permeability which permits the infection to pass from the gingival tissues to the rest of the body. Numerous reviews indicate that the intra-amniotic levels of prostaglandins especially prostaglandin E-2 (PGE2) and tumor necrosis factor (TNF- $\alpha$ ) rise steadily throughout pregnancy until a critical threshold is reached to induce labor, cervical dilation, and delivery. These molecules are also produced within the diseased periodontium which can escape into the general circulation together with other LPS, peptidoglycan fragments, and hydrolytic enzymes [58, 71]. This can lead to translocation of periodontal pathogens to the fetoplacental unit precipitating PT labour. It has also been observed that during the second trimester of pregnancy, the proportion of Gram-negative anaerobic bacteria in dental plaque increases with respect to aerobic bacteria. Also, the second-trimester level of serum antibody against $P$. gingivalis has been related to PLBW [72].

Blood samples from the umbilical cord of newborns when analyzed, showed that premature babies had a specific IgM against oral pathogens significantly higher than term babies. Provided that maternal IgM does not pass through the placental barrier, these results suggest a direct intrauterine foetal exposure to these bacteria that may be the responsible for the premature birth [73].

On the other hand it is also suggested that prematurity risk may increase when the foetus is exposed to periodontal bacteria and an inflammatory response is generated. It has been postulated that periodontal infection may cause bacteremia including the circulation of LPS that might trigger a host immune response exaggerating the effects of low-grade inflammation in other organs [74]. LPS from pathogens associated with periodontitis may also activate placental release of TNF- $\alpha$ and Interleukin (IL)- 1 [57].

The role of the host's inflammatory response appears to be the critical determinant of susceptibility and severity [75]. It has been reported that the levels of CRP are dependent on the severity of chronic periodontal infection and are significantly higher in women with pre-eclampsia [76]. A study analyzed the umbilical cord blood of newborns and measured protein $\mathrm{C}$ reactive, IL-1, IL-6, TNF- $\alpha$, PGE2 and IgM levels against periodontal pathogens. The risk of prematurity was higher when $\operatorname{IgM}$ was detected against at least one periodontal pathogen and even higher when high levels of inflammatory mediators were measured [77]. Not only IgM but also IgG has been found to increase the risk of LBW. Dasanayake et al. [78] found that women with elevated second-trimester serum IgG levels against $P$. gingivalis were more likely to give birth to a LBW infant. The maternal serum IgG was consistently higher for women with periodontitis. On the other hand, Madianos et al. [59] reported higher incidence of PT births was observed in the absence of a maternal IgG response to microorganisms associated with gin- givitis coupled with a fetal $\operatorname{IgM}$ response to $P$ gingivalis, $T$ denticola, and $T$. forsythia. Given the fact that a broad range of antibody responses to periodontal pathogens has been observed in patients, the association between such titers and pregnancy complications remains speculative at the current time [79].

Collectively, these animal and clinical studies clearly indicate an association between periodontal infection and adverse pregnancy outcomes. Although no definitive relationship has been established, a model can be envisaged wherein chronic periodontal infection could mediate this systemic effect through one or more of the following mechanisms: (i) Translocation of periodontal pathogens to the fetoplacental unit, (ii) Action of a periodontal reservoir of LPS on the fetoplacental unit, or (iii) Action of a periodontal reservoir of inflammatory mediators (IL-1, IL-6, TNF- $\alpha$, PGE2) on the fetoplacental unit [38]. The association between periodontal disease and PT/LBW may reflect the patient's altered immune-inflammatory trait that places the patient at risk for both conditions. Thus, periodontitis may be a marker for PT delivery susceptibility as well as a potential risk factor.

\section{CONCLUSION}

Through reviewing the various published literature, it is seen that women having PT/LBW delivery have a higher prevalence and severity of periodontitis, more gingival inflammation and also higher levels of putative periodontal pathogens. When combined with animal studies showing adverse effects of experimental periodontitis on the fetus and the data supporting biologically plausible interactive mechanisms, the evidence strongly suggests that periodontal infection may have a significant negative impact on pregnancy outcome. Women especially those who belong to the high risk category, should be encouraged to achieve a high level of oral hygiene prior to becoming pregnant and throughout their pregnancies.

\section{LIST OF ABBREVIATIONS}

$\begin{array}{lll}\text { BMI } & = & \text { Body mass index } \\ \text { DNA } & = & \text { Deoxyribonucleic acid } \\ \mathrm{IL} & = & \text { Interleukin } \\ \mathrm{Ig} & = & \text { Immunoglobulin } \\ \mathrm{IUGR} & = & \text { Intrauterine growth retardation } \\ \text { LPS } & = & \text { Lipopolysaccharides } \\ \text { LBW } & = & \text { Low birth weight } \\ \text { MIA } & = & \text { Maternal immune activation } \\ \text { MMP } & = & \text { Matrix Metalloproteinase } \\ \text { PT } & = & \text { Preterm } \\ \text { PLBW } & = & \text { Preterm low birth weight } \\ \text { PG } & = & \text { Prostaglandin } \\ \text { RCT } & = & \text { Randomized clinical trial } \\ \text { TNF } & = & \text { Tumour necrosis factor } \\ \text { WHO } & = & \text { World health organization }\end{array}$




\section{CONFLICT OF INTEREST}

None declared.

\section{ACKNOWLEDGEMENT}

None declared.

\section{REFERENCES}

[1] The incidence of low birth weight: an update. World Health Organ Wkly Epidemiol Rec [Weekly Report] 1984; 59: 205-11.

[2] Goldenberg RL, Culhane JF, Iams JD, Romero R. Epidemiology and causes of preterm birth. Lancet 2008; 371(9606): 75-84.

[3] Cruz SS, Costa Mda C, Gomes Filho IS, Vianna MI, Santos CT. Maternal periodontal disease as a factor associated with low birth weight. Rev Saude Publica 2005; 39(5): 782-7.

[4] The incidence of low birth weight: a critical review of available information. World Health Stat Q 1980; 33(3): 197-224.

[5] Goldenberg RL, Cliver SP, Mulvihill FX, et al. Medical, psychosocial, and behavioral risk factors do not explain the increased risk for low birth weight among black women. Am J Obstet Gynecol 1996; 175(5): 1317-24.

[6] Goldenberg RL, Goepfert AR, Ramsey PS. Biochemical markers for the prediction of preterm birth. Am J Obstet Gynecol 2005; 192(5 Suppl): S36-46.

[7] Copper RL, Goldenberg RL, Das A, et al. The preterm prediction study: maternal stress is associated with spontaneous preterm birth at less than thirty-five weeks' gestation. National Institute of Child Health and Human Development Maternal-Fetal Medicine Units Network. Am J Obstet Gynecol 1996; 175(5): 1286-92.

[8] Nordstrom ML, Cnattingius S. Effects on birthweights of maternal education, socio-economic status, and work-related characteristics. Scand J Soc Med 1996; 24(1): 55-61.

[9] Verkerk PH, van Noord-Zaadstra BM, Florey CD, de Jonge GA, Verloove-Vanhorick SP. The effect of moderate maternal alcohol consumption on birth weight and gestational age in a low risk population. Early Hum Dev 1993; 32(2-3): 121-9.

[10] Marakoglu I, Gursoy UK, Marakoglu K, Cakmak H, Ataoglu T. Periodontitis as a risk factor for preterm low birth weight. Yonsei Med J 2008; 49(2): 200-3.

[11] Romero BC, Chiquito CS, Elejalde LE, Bernardoni CB. Relationship between periodontal disease in pregnant women and the nutritional condition of their newborns. J Periodontol 2002; 73(10): 1177-83.

[12] Conde-Agudelo A, Rosas-Bermudez A, Kafury-Goeta AC. Birth spacing and risk of adverse perinatal outcomes: a meta-analysis. JAMA 2006; 295(15): 1809-23.

[13] Mercer BM, Goldenberg RL, Moawad AH, et al. The preterm prediction study: effect of gestational age and cause of preterm birth on subsequent obstetric outcome. National Institute of Child Health and Human Development Maternal-Fetal Medicine Units Network. Am J Obstet Gynecol 1999; 181(5 Pt 1): 1216-21.

[14] Romero R, Espinoza J, Kusanovic JP, et al. The preterm parturition syndrome. BJOG 2006; 113 Suppl 3: 17-42.

[15] Goldenberg RL, Tamura T. Prepregnancy weight and pregnancy outcome. JAMA 1996; 275(14): 1127-8.

[16] Hendler I, Goldenberg RL, Mercer BM, et al. The Preterm Prediction Study: association between maternal body mass index and spontaneous and indicated preterm birth. Am J Obstet Gynecol 2005; 192(3): 882-6.

[17] Hediger ML, Scholl TO, Belsky DH, Ances IG, Salmon RW. Patterns of weight gain in adolescent pregnancy: effects on birth weight and preterm delivery. Obstet Gynecol 1989; 74(1): 6-12.

[18] Newman RB, Goldenberg RL, Moawad AH, et al. Occupational fatigue and preterm premature rupture of membranes. National Institute of Child Health and Human Development Maternal-Fetal Medicine, Units Network. Am J Obstet Gynecol 2001; 184(3): 43846.

[19] Pompeii LA, Savitz DA, Evenson KR, Rogers B, McMahon M. Physical exertion at work and the risk of preterm delivery and small-for-gestational-age birth. Obstet Gynecol 2005; 106(6): 1279-88.

[20] Gavin NI, Gaynes BN, Lohr KN, Meltzer-Brody S, Gartlehner G, Swinson T. Perinatal depression: a systematic review of prevalence and incidence. Obstet Gynecol 2005; 106(5 Pt 1): 1071-83.
Dayan J, Creveuil C, Marks MN, et al. Prenatal depression, prenatal anxiety, and spontaneous preterm birth: a prospective cohort study among women with early and regular care. Psychosom Med 2006; 68(6): 938-46.

Hoffman S, Hatch MC. Stress, social support and pregnancy outcome: a reassessment based on recent research. Paediatr Perinat Epidemiol 1996; 10(4): 380-405.

[23] Wald NJ, Hackshaw AK. Cigarette smoking: an epidemiological overview. Br Med Bull 1996; 52(1): 3-11.

[24] Goldenberg RL, Hauth JC, Andrews WW. Intrauterine infection and preterm delivery. N Engl J Med 2000; 342(20): 1500-7.

[25] Gibbs RS. The relationship between infections and adverse pregnancy outcomes: an overview. Ann Periodontol 2001; 6(1): 153-63.

[26] Sorokin Y, Romero R, Mele L, et al. Maternal serum interleukin-6, C-reactive protein, and matrix metalloproteinase- 9 concentrations as risk factors for preterm birth $<32$ weeks and adverse neonatal outcomes. Am J Perinatol 2010; 27(8): 631-40.

[27] Yoon BH, Romero R, Park JS, et al. Fetal exposure to an intraamniotic inflammation and the development of cerebral palsy at the age of three years. Am J Obstet Gynecol 2000; 182(3): 675-81.

[28] Romero R, Gomez R, Ghezzi F, et al. A fetal systemic inflammatory response is followed by the spontaneous onset of preterm parturition. Am J Obstet Gynecol 1998; 179(1): 186-93.

[29] Kassal R, Anwar M, Kashlan F, Smulian J, Hiatt M, Hegyi T. Umbilical vein interleukin-6 levels in very low birth weight infants developing intraventricular hemorrhage. Brain Dev 2005; 27(7): 483-7.

[30] Heep A, Behrendt D, Nitsch P, Fimmers R, Bartmann P, Dembinski J. Increased serum levels of interleukin 6 are associated with severe intraventricular haemorrhage in extremely premature infants. Arch Dis Child Fetal Neonatal Ed 2003; 88(6): F501-4.

[31] Ghezzi F, Franchi M, Raio L, et al. Elevated amniotic fluid Creactive protein at the time of genetic amniocentesis is a marker for preterm delivery. Am J Obstet Gynecol 2002; 186(2): 268-73.

[32] Joram N, Boscher C, Denizot S, et al. Umbilical cord blood procalcitonin and $\mathrm{C}$ reactive protein concentrations as markers for early diagnosis of very early onset neonatal infection. Arch Dis Child Fetal Neonatal Ed 2006; 91(1): F65-6.

[33] Maymon E, Romero R, Pacora P, et al. Evidence of in vivo differential bioavailability of the active forms of matrix metalloproteinases 9 and 2 in parturition, spontaneous rupture of membranes, and intra-amniotic infection. Am J Obstet Gynecol 2000; 183(4): 887-94.

[34] Schulz CG, Sawicki G, Lemke RP, Roeten BM, Schulz R, Cheung PY. MMP-2 and MMP-9 and their tissue inhibitors in the plasma of preterm and term neonates. Pediatr Res 2004; 55(5): 794-801.

[35] Winkler M, Fischer DC, Hlubek M, van de Leur E, Haubeck HD, Rath W. Interleukin-1beta and interleukin-8 concentrations in the lower uterine segment during parturition at term. Obstet Gynecol 1998; 91(6): 945-9.

[36] Romero R, Mazor M, Sepulveda W, Avila C, Copeland D, Williams J. Tumor necrosis factor in preterm and term labor. Am J Obstet Gynecol 1992; 166(5): 1576-87.

[37] Sehringer B, Schafer WR, Wetzka B, et al. Formation of proinflammatory cytokines in human term myometrium is stimulated by lipopolysaccharide but not by corticotropin-releasing hormone. J Clin Endocrinol Metab 2000; 85(12): 4859-65.

[38] McGaw T. Periodontal disease and preterm delivery of low-birthweight infants. J Can Dent Assoc 2002; 68(3): 165-9.

[39] Dussault G, Sheiham A. Medical theories and professional development. The theory of focal sepsis and dentistry in early twentieth century Britain. Soc Sci Med 1982; 16(15): 1405-12.

[40] Pihlstrom BL, Michalowicz BS, Johnson NW. Periodontal diseases. Lancet 2005; 366(9499): 1809-20.

[41] Contreras A, Herrera J, Soto J, Arce R, Jaramillo A, Botero J. Periodontitis is associated with preeclampsia in pregnant women. $\mathrm{J}$ Periodontol 2006; 77(2): 182-8.

[42] Offenbacher S, Katz V, Fertik G, et al. Periodontal infection as a possible risk factor for preterm low birth weight. J Periodontol 1996; 67(10 Suppl): 1103-13.

[43] Dasanayake AP. Poor periodontal health of the pregnant woman as a risk factor for low birth weight. Ann Periodontol 1998; 3(1): 20612.

[44] Mobeen N, Jehan I, Banday N, et al. Periodontal disease and adverse birth outcomes: a study from Pakistan. Am J Obstet Gynecol 2008; 198(5): 514. e1-8. 
[45] Saddki N, Bachok N, Hussain NH, Zainudin SL, Sosroseno W. The association between maternal periodontitis and low birth weight infants among Malay women. Community Dent Oral Epidemiol 2008; 36(4): 296-304.

[46] Pitiphat W, Joshipura KJ, Gillman MW, Williams PL, Douglass CW, Rich-Edwards JW. Maternal periodontitis and adverse pregnancy outcomes. Community Dent Oral Epidemiol 2008; 36(1): 3-11.

[47] Moliterno LF, Monteiro B, Figueredo CM, Fischer RG. Association between periodontitis and low birth weight: a case-control study. J Clin Periodontol 2005; 32(8): 886-90.

[48] Khader Y, Al-shishani L, Obeidat B, et al. Maternal periodontal status and preterm low birth weight delivery: a case-control study. Arch Gynecol Obstet 2009; 279(2): 165-9.

[49] Guimaraes AN, Silva-Mato A, Miranda Cota LO, Siqueira FM, Costa FO. Maternal periodontal disease and preterm or extreme preterm birth: an ordinal logistic regression analysis. J Periodontol 2010; 81(3): 350-8.

[50] Ryu JI, Oh K, Yang H, et al. Health behaviors, periodontal conditions, and periodontal pathogens in spontaneous preterm birth: a case-control study in Korea. J Periodontol 2010; 81(6): 855-63.

[51] Baskaradoss JK, Geevarghese A, Kutty VR. Maternal periodontal status and preterm delivery: a hospital based case-control study. J Periodontal Res 2011; 46(5): 542-9.

[52] Jeffcoat MK, Hauth JC, Geurs NC, et al. Periodontal disease and preterm birth: results of a pilot intervention study. J Periodontol 2003; 74(8): 1214-8.

[53] Lopez NJ, Smith PC, Gutierrez J. Periodontal therapy may reduce the risk of preterm low birth weight in women with periodontal disease: a randomized controlled trial. J Periodontol 2002; 73(8): 911-24.

[54] Tarannum F, Faizuddin M. Effect of periodontal therapy on pregnancy outcome in women affected by periodontitis. J Periodontol 2007; 78(11): 2095-103.

[55] Michalowicz BS, Hodges JS, DiAngelis AJ, et al. Treatment of periodontal disease and the risk of preterm birth. N Engl J Med 2006; 355(18): 1885-94.

[56] Weidlich P, Moreira $\mathrm{CH}$, Fiorini $\mathrm{T}$, et al. Effect of nonsurgical periodontal therapy and strict plaque control on preterm/low birth weight: a randomized controlled clinical trial. Clin Oral Investig 2012. [Epub ahead of print]

[57] Offenbacher S, Jared HL, O'Reilly PG, et al. Potential pathogenic mechanisms of periodontitis associated pregnancy complications. Ann Periodontol 1998; 3(1): 233-50.

[58] Loesche WJ. Association of the oral flora with important medical diseases. Curr Opin Periodontol 1997; 4: 21-8.

[59] Madianos PN, Lieff S, Murtha AP, et al. Maternal periodontitis and prematurity. Part II: Maternal infection and fetal exposure. Ann Periodontol 2001; 6(1): 175-82.

[60] Han YW, Redline RW, Li M, Yin L, Hill GB, McCormick TS. Fusobacterium nucleatum induces premature and term stillbirths in pregnant mice: implication of oral bacteria in preterm birth. Infect Immun 2004; 72(4): 2272-9.

[61] Lin D, Smith MA, Elter J, et al. Porphyromonas gingivalis infection in pregnant mice is associated with placental dissemination, an increase in the placental Th1/Th2 cytokine ratio, and fetal growth restriction. Infect Immun 2003; 71(9): 5163-8.
[62] Kemp MW, Saito M, Newnham JP, Nitsos I, Okamura K, Kallapur SG. Preterm birth, infection, and inflammation advances from the study of animal models. Reprod Sci 2010; 17(7): 619-28.

[63] Chambrone L, Guglielmetti MR, Pannuti CM, Chambrone LA. Evidence grade associating periodontitis to preterm birth and/or low birth weight: I. a systematic review of prospective cohort studies. J Clin Periodontol 2011; 38(9): 795-808.

[64] Chambrone L, Pannuti CM, Guglielmetti MR, Chambrone LA. Evidence grade associating periodontitis with preterm birth and/or low birth weight: II. a systematic review of randomized trials evaluating the effects of periodontal treatment. J Clin Periodontol 2011; 38(10): 902-14.

[65] Conde-Agudelo A, Villar J, Lindheimer M. Maternal infection and risk of preeclampsia: systematic review and metaanalysis. Am J Obstet Gynecol 2008; 198(1): 7-22.

[66] Pimentel Lopes De Oliveira GJ, Amaral FL, Chaves De Souza JA, Ribeiro CM, Cirelli JA. Effect of periodontal treatment on the incidence of preterm delivery: a systematic review. Minerva Stomatol 2010; 59(10): 543-50.

[67] Khader YS, Ta'ani Q. Periodontal diseases and the risk of preterm birth and low birth weight: a meta-analysis. J Periodontol 2005; 76(2): 161-5.

[68] Vergnes JN, Sixou M. Preterm low birth weight and maternal periodontal status: a meta-analysis. Am J Obstet Gynecol 2007; 196(2): 135 e1-7.

[69] Fogacci MF, Vettore MV, Leao AT. The effect of periodontal therapy on preterm low birth weight: a meta-analysis. Obstet Gynecol 2011; 117(1): 153-65.

[70] Kim AJ, Lo AJ, Pullin DA, Thornton-Johnson DS, Karimbux NY. Scaling and root planing treatment for periodontitis to reduce preterm birth and low birth weight: a systematic review and metaanalysis of randomized controlled trials. J Periodontol 2012.

[71] Page RC. The role of inflammatory mediators in the pathogenesis of periodontal disease. J Periodontal Res 1991; 26(3 Pt 2): 230-42.

[72] Dasanayake AP, Russell S, Boyd D, Madianos PN, Forster T, Hill E. Preterm low birth weight and periodontal disease among African Americans. Dent Clin North Am 2003; 47(1): 115-25, x-xi.

[73] Madianos PN, Bobetsis GA, Kinane DF. Is periodontitis associated with an increased risk of coronary heart disease and preterm and/or low birth weight births? J Clin Periodontol 2002; 29 (Suppl 3): 2236; discussion 7-8.

[74] Dortbudak O, Eberhardt R, Ulm M, Persson GR. Periodontitis, a marker of risk in pregnancy for preterm birth. J Clin Periodontol 2005; 32(1): 45-52.

[75] Fowler EB, Breault LG, Cuenin MF. Periodontal disease and its association with systemic disease. Mil Med 2001; 166(1): 85-9.

[76] Herrera JA, Parra B, Herrera E, et al. Periodontal disease severity is related to high levels of C-reactive protein in pre-eclampsia. J Hypertens 2007; 25(7): 1459-64.

[77] Boggess KA. Pathogenicity of periodontal pathogens during pregnancy. Am J Obstet Gynecol 2005; 193(2): 311-2.

[78] Dasanayake AP, Boyd D, Madianos PN, Offenbacher S, Hills E. The association between Porphyromonas gingivalis-specific maternal serum $\operatorname{IgG}$ and low birth weight. J Periodontol 2001; 72(11): 1491-7.

[79] Jarjoura K, Devine PC, Perez-Delboy A, Herrera-Abreu M, D'Alton M, Papapanou PN. Markers of periodontal infection and preterm birth. Am J Obstet Gynecol 2005; 192(2): 513-9.

(C) Baskaradoss et al.; Licensee Bentham Open.

This is an open access article licensed under the terms of the Creative Commons Attribution Non-Commercial License (http://creativecommons.org/licenses/by-nc/3.0/) which permits unrestricted, non-commercial use, distribution and reproduction in any medium, provided the work is properly cited. 